\title{
Does Unemployment Lead to a Less Healthy Lifestyle?
}

\author{
Kaiser, Micha; Bauer, Jan Michael; Sousa-Poza, Alfonso
}

Document Version

Accepted author manuscript

Published in:

Applied Economics Letters

DOI:

10.1080/13504851.2016.1231888

Publication date:

2017

Citation for published version (APA):

Kaiser, M., Bauer, J. M., \& Sousa-Poza, A. (2017). Does Unemployment Lead to a Less Healthy Lifestyle? Applied Economics Letters, 24(12), 815-819. https://doi.org/10.1080/13504851.2016.1231888

Link to publication in CBS Research Portal

\section{General rights}

Copyright and moral rights for the publications made accessible in the public portal are retained by the authors and/or other copyright owners and it is a condition of accessing publications that users recognise and abide by the legal requirements associated with these rights.

Take down policy

If you believe that this document breaches copyright please contact us (research.lib@cbs.dk) providing details, and we will remove access to the work immediately and investigate your claim. 


\section{Does Unemployment Lead to a Less Healthy Lifestyle? Micha Kaiser, Jan Michael Bauer, and Alfonso Sousa-Poza}

Journal article (Post print version)

Cite: Does Unemployment Lead to a Less Healthy Lifestyle? / Kaiser, Micha; Bauer, Jan Michael; Sousa-Poza, Alfonso. In: Applied Economics Letters, २०16.

This is an Accepted Manuscript of an article published by Taylor \& Francis in Applied Economics Letters on 25 September 2016, available online: http://www.tandfonline.com/10.1080/13504851.2016.1231888

Uploaded to Research@CBS: December 2016 


\title{
Does unemployment lead to a less healthy lifestyle?
}

\author{
Micha Kaiser ${ }^{*}$, Jan Michael Bauer ${ }^{+}$, Alfonso Sousa-Poza ${ }^{*}$ \\ *Institute for Health Care and Public Management (530), University of Hohenheim, Germany \\ ${ }^{+}$Department for Intercultural Communication and Management, Copenhagen Business School, \\ Denmark
}

\begin{abstract}
:
In this paper, we use 22 years of data from the German Socio-Economic Panel and information on plant closures to investigate the effects of unemployment on four indicators of unhealthy lifestyles: diet, alcohol consumption, smoking, and (a lack of) physical activity. In contrast to much of the existing literature, which unlike our analysis is unable to assess causality, our results provide little evidence that unemployment gives rise to unhealthy lifestyles.
\end{abstract}

Keywords: Unhealthy lifestyles, unemployment, Germany, panel data

JEL codes: B23, I12, J64

${ }^{\perp}$ Corresponding author

UNIVERSITY OF HOHENHEIM

Institute for Health Care and Public Management (530A)

Fruwirthstr. 48

70599 Stuttgart

Germany

Tel: +49(0)711459 22565

Email:micha.kaiser @uni-hohenheim.de 


\section{Does unemployment lead to a less}

\section{healthy lifestyle?}

\section{Introduction}

Poor lifestyle choices incur large social costs in terms of health care and individual well-being (Bouchery et al., 2011; Scarborough et al., 2011, p. 2). Yet, although the effect of unemployment on unhealthy lifestyles is extensively discussed in the literature, drawing general conclusions remains difficult. Whereas most studies find that unemployment increases risky health behaviours (Ettner, 1997; Montgomery et al., 1998; Mossakowski, 2008; Dave and Kelly,2012), others cannot confirm, or even contradict, these findings (Khan et al., 2002; Schmitz, 2011; Arcaya et al., 2014). In addition, earlier studies tend to suffer from the endogeneity inherent in standard regression models. To address this problem, a few studies estimate causal relations by exploiting natural experiments like plant closures (Debet al., 2011; Schmitz, 2011), in which job loss cannot be attributed to individual behaviour and the shutdown is unlikely to be related to any one individual's lifestyle choices.

In this paper, we use 22 years of data from the German Socio-Economic Panel (GSOEP) to estimate the effects of unemployment on four health behaviours: diet, alcohol consumption, smoking, and (lack of) physical activity. To highlight the importance of accounting for endogeneity, we use plant closure as an exogenous reason for unemployment. The analysis 
thus extends the literature by assessing the outcome of a range of lifestyle indicators and by using non-parametric estimation methods to account for unobserved heterogeneity and the ordinal nature of the data.

\section{Methods and Data}

The analysis is based on GSOEP data from 1991 to 2012 and restricted to individuals aged 25 to 60. Because we are interested in the effect of job loss, the sample contains only individuals who were employed at least once during the survey period. The basic model, which extends the approach taken by Schmitz (2011), is expressed by the following functional form:

$$
Y_{i t}=f\left(X_{i t}^{p c}, X_{i t}^{o r}, X_{i(t-1)}^{\prime A V}, \mu_{i}, e_{i t}\right)
$$

Here, the subscripts indicate individual $i$ and time $t$, and the dependent variables are as described in Table 1. The main independent variables indicate job loss, with $X_{i t}^{p c}$ equalling 1 if a job loss occurred because of plant closure (exogenous layoff) and $X_{i t}^{\text {or }}$ equalling 1 if for some other reason, such as by mutual agreement (endogenous layoff). $X_{i(t-1)}^{\prime A V}$ captures lagged sociodemographic characteristics (i.e. age, number of children, household income, employment status, marital status, education, job type, and health insurance status) to control for pre-job loss differences without closing all possible channels for the effect on our outcome variable in period $t{ }^{1}$ The individual fixed effect $\mu_{i}$ (not used in the finite mixture model) captures unobserved characteristics, while $e_{i t}$ is the disturbance term. To estimate the ordinal measures, we apply a blow-up and cluster estimator (BUC), shown to be the most efficient for our research design (Baetschmann et al., 2015). Because smoking is measured in numbers of

\footnotetext{
${ }^{1}$ Thus, for example, a job loss can be assumed to have a direct (negative) income effect. If we controlled for income in period $t$ rather than $t-1$, our income variable might be correlated with the job loss variable, making it impossible to assess the causal impact of (exogenous) unemployment on health behavior.
} 
tobacco units per day and the data structure suggests more than one underlying density function (see Fig. 1), we use a finite mixed model (FMM) approach for the estimation.

\section{- $\quad$ Fig 1 -}

\section{- Table 1 -}

\section{Results}

The results for the ordinally scaled variables (Table 2 ) indicate that, in general, the coefficients for the exogenous versus the endogenous layoffs differ substantially, although the fact that both regressors differ heterogeneously requires further explanation. For diet (i.e. the effect of unemployment on eating habits), we observe no significant effect when unemployment is treated endogenously. However, if individuals lose their jobs because of plant closure (exogenous layoff), their diets tend to become more health conscious, suggesting that unemployment may actually lead to better eating habits. Such an outcome may be attributable to the lower opportunity cost of the time needed to maintain a healthy diet. The lack of significance in the endogenous case suggests the existence of reverse causality, meaning that individuals with unhealthy eating habits (and their correlates such as obesity) are more likely to lose their jobs. A similar result is reported in Schmitz (2011), who shows that those in ill health select into unemployment. For alcohol use, the endogenous regressor suggests a significant impact of unemployment on alcohol consumption. This relationship is, however, not evident if we look at individuals that lost their jobs due to plant closure. In contrast to other studies (Mossakowski, 2008; Ettner, 1997), we find no effect of unemployment on drinking behaviour. For physical activity, measured here as engagement in sports, the endogenous and exogenous coefficients point in different directions. That is, unemployment seems to have a beneficial effect on physical activity by allowing individuals more free time to engage in it. On the other hand, the endogenous case suggests that less sporty individuals are more likely to be laid off. 


\section{- Table 2 -}

The results for the numerically scaled outcome variable smoking (Table 3 ) are estimated using two different finite mixture models, each made up of two components (see Fig. 2). In the first, we estimate tobacco units per day assuming a negative binomial distribution (NEGBIN); in the second, we assume a normal distribution (NORMAL). This NORMAL model is restricted to individuals that smoked at least one tobacco unit per day during the sample period (i.e. were already smokers ${ }^{2}$ ), meaning that marginal changes in tobacco consumption inferred from these estimates reflect the direct effect on smoking behaviour. For the endogenous case, we obtain a significant coefficient in both models: NEGBIN yields a positive and significant relation for individuals who smoked very few tobacco units per day (component one), while NORMAL reveals a similar link for heavy smokers (component two). Interestingly, neither model shows any effect for the group of regular smokers ${ }^{3}$, who are covered by one component in each model. For the exogenous regressors, however, we obtain no significant coefficient in either model, thereby finding no evidence that unemployment has an impact on tobacco consumption. These findings are in line with the estimation results for the pooled OLS model, which is included as a robustness check. Again, the estimation results suggest reverse causality, i.e. individuals with a higher propensity to smoke are more likely to get laid off.

\section{- Table 3 -}

\section{- $\quad$ Fig 2 -}

However, the effect of unemployment on the lifestyle variables might be sensitive to the type of employment or personal conditions. We expect a 25 year-old single being laid off after a failed start-up to respond differently than a 45 year-old married mechanic. Furthermore, some

\footnotetext{
${ }^{3}$ Regular smokers consumed around 15 tobacco units per day.
} 
unhealthy habits, like smoking, can be expensive and the reduction in income might limit the ability to change behaviour. We test this by incorporating interaction terms for age, marriage, and household income with (exogenous/endogenous) layoff in each case. As job type is expected to show little within variation, particularly when interacted with layoff, we estimate two separate regressions for blue and white collar workers. We report the main findings in appendix table $\mathrm{A} 1$.

There is scant evidence for age-dependent heterogeneous effects related to diet and alcohol consumption. In the case of risky sport behaviour, we find age to have a negative and statistically significant effect in the endogenous case. Including the age interaction for smoking yields the following pattern: in the endogenous case, we find an overall positive effect after the age of 29 , while the overall effect for the exogenous case turns negative at the age of 48 . This striking result suggests a very diverse response of smoking behavior to unemployed depending on age, which is partly offset in the average effect.

Marriage seems to mediate the effect of unemployment differently for sport and smoking. While only singles seem to improve their physical activity after an exogenous layoff, married people smoke significantly less compared to their single counterparts.

In contrast to the aggregated regression, we observe no significant effect of plant closure on diets for both job types. Interestingly, the negative effect on risky alcohol, physical activity, and smoking behavior of exogenous layoffs is mainly driven by blue collar workers, while the white collar sample even shows more risky smoking behavior in response to exogenous unemployment.

For physical activity and risky alcohol consumption we find a positive interaction effect with household income. These findings support the idea that budget constrains might be a limiting factor for pursuing some types of risky behavior. 


\section{Discussion}

In this paper, we estimate the impact of unemployment on healthy lifestyles by using plant closures as an exogenous event that, in contrast to regular layoffs, is unlikely to be subject to a reverse causality bias. ${ }^{4}$ Specifically, by comparing both exogenous and endogenous regressors, we are able to assess the magnitude of this bias. Our estimates, unlike those of earlier studies, reveal no negative impact of unemployment on any of the four lifestyle indicators assessed (diet, alcohol consumption, physical activity, and smoking). In fact, they imply a positive effect of unemployment on diet and physical activity, which, given the time intensity of ensuring a healthy diet and sufficient physical activity, is probably related to the lower opportunity costs of time during unemployment. This conclusion is also supported by research that shows a procyclical behaviour of unhealthy lifestyles (e.g. Freeman, 1999; Ettner, 1997). We additionally test for long-run effects of job loss by considering two periods of unemployment (results available on request). For smoking and sport, only endogenous layoffs have a persistent effect over two periods.

Overall, our findings stand in contrast to those of most previous studies (Montgomeryet al., 1998; Dave and Kelly, 2012; Arcaya et al., 2014), which too often fail to account for the endogeneity bias. Throughout all our estimations, the endogenous coefficients, unlike the exogenous coefficients (plant closure), are biased in a positive direction. We therefore conclude that individuals who make unhealthier lifestyle decisions are more likely to be laid off. This conclusion, together with our failure to observe any negative causal impact of unemployment, suggests that such policy interventions as the German "Equity in Health"

\footnotetext{
${ }^{4}$ To test for the possible anticipation of a plant closure, we match people experiencing a plant closure in $t+1$ with employees that remain employed in $t+1$ based on a set of observables other than lifestyle. We find no significant difference in the means of the four lifestyle variables in period $t$.
} 
cooperation network (Kooperationsverbund Gesundheitliche Chancengleichheit ${ }^{5}$ ), which is aimed specifically at influencing the behaviour of unemployed individuals, may come too late. Policy-makers should thus shift their efforts to preventive measures that target unhealthy lifestyles in the whole population, which would not only improve health in general but might also mitigate the risk of individuals with unhealthy lifestyles becoming unemployed.

\footnotetext{
${ }^{5}$ See http://www.gesundheitliche-chancengleichheit.de
} 


\section{References}

Arcaya, M., Glymour, M. M., Christakis, N. A., Kawachi, I., Subramanian, S., 2014. Individual and spousal unemployment as predictors of smoking and drinking behavior. Soc. Sci. Med. 110, 89-95.

Baetschmann, G., Staub, K. E., Winkelmann, R., 2015. Consistent estimation of the fixed effects ordered logit model. J. Royal Statistical Society A 178(3), 685-703.

Bouchery, E. E., Harwood, H. J., Sacks, J. J., Simon, C. J., Brewer, R. D., 2011. Economic costs of excessive alcohol consumption in the U.S., 2006. Am. J. Prev. Med. 41(5), 516-524.

Dave, D. M., Kelly, I. R., 2012. How does the business cycle affect eating habits? Soc. Sci. Med. 74, 254-262.

Deb, P., Gallo, W. T., Ayyagari, P., Fletcher, J. M., Sindelar, J. L., 2011. The effect of job loss on overweight and drinking. J. Health Econ. 30, 317-327.

Ettner, S. L., 1997. Measuring the human cost of a weak economy: does unemployment lead to alcohol abuse. Soc. Sci. Med. 44(2), 251-260.

Freeman, D. G., 1999. A note onEconomic conditions and alcohol problems. Journal of Health Economics. 18, 661-670.

Khan, S., Murray, R. P., Barnes, G. E., 2002. A structural equation model of the effect of poverty and unemployment on alcohol abuse. Addict. Behav. 27, 405-423.

Montgomery, S. M., Cook, D. G., Bartley, M. L., Wadsworth, M. E., 1998. Unemployment, cigarette smoking, alcohol consumption and body weight in young British men. Eur. J. Public Health, 8(1), 21-27.

Mossakowski, K. N., 2008. Is the duration of poverty and unemployment a risk factor for heavy drinking. Soc. Sci. Med. 67, S947-S955. 
Scarborough, P., Bhatnagar, P., Wickramasinghe, K. K., Allender, S., Foster, C., Rayner, M., 2011. The economic burden of ill health due to diet, physical inactivity, smoking, alcohol and obesity in the UK: an update to 2006-07 NHS costs. J. Public Health 33(4), 527-535.

Schmitz, H., 2011. Why are the unemployed in worse health? The causal effect of unemployment on health. Labor Econ. 18, 71-78. 
Figures

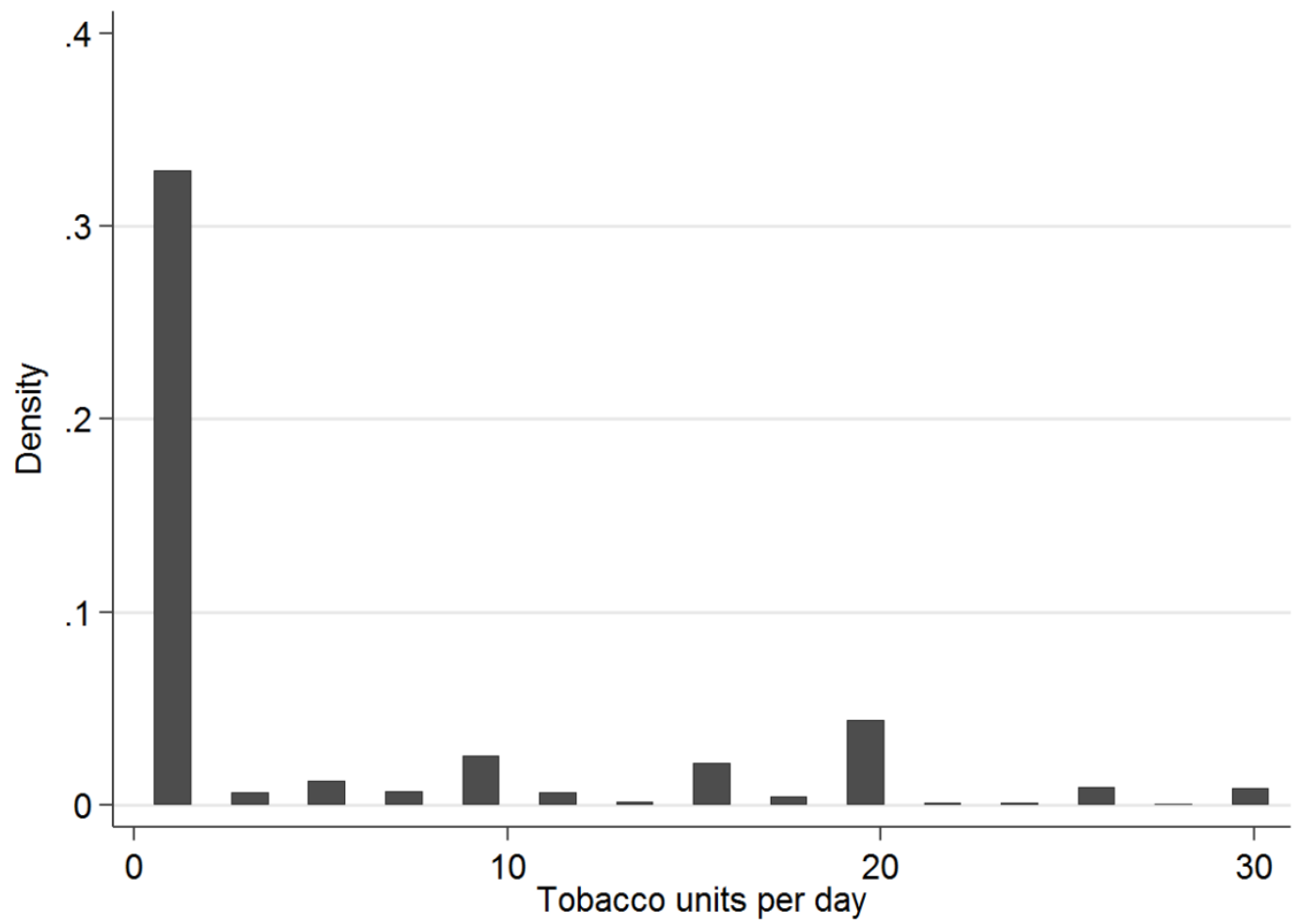

Fig. 1. Distribution of tobacco units per day. 


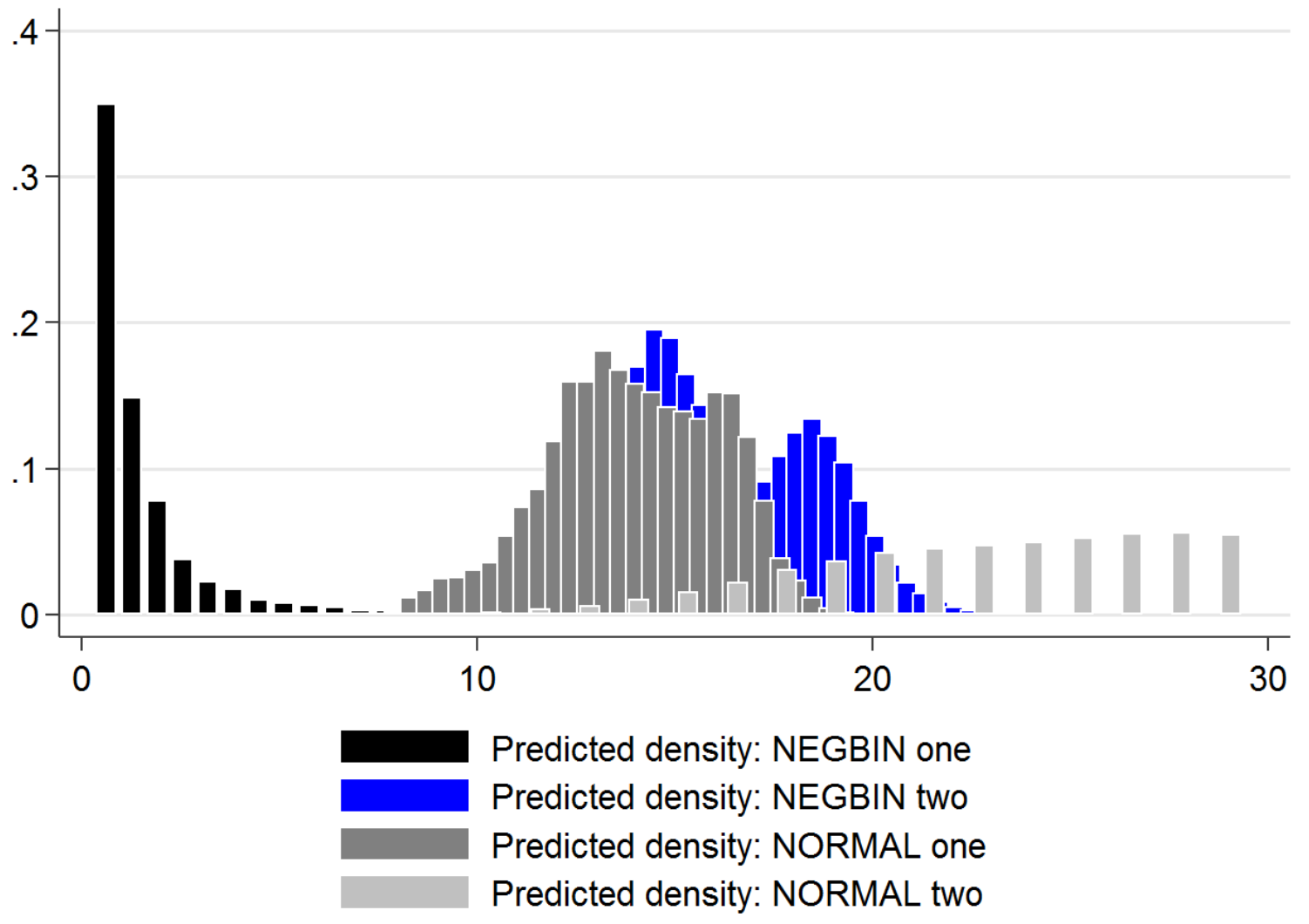

Fig. 2. Predicted densities for each FFM model and associated component. 


\section{Tables}

\section{Table 1}

Description of dependent variables and estimators

\begin{tabular}{|c|c|c|c|c|}
\hline & \multicolumn{4}{|c|}{ Variable } \\
\hline & (1) & (2) & (3) & (4) \\
\hline & Diet & Alcohol & $\begin{array}{l}\text { Physical activity } \\
\text { (sports) }\end{array}$ & Smoking \\
\hline Type of measure & $\begin{array}{l}\text { 4-point ordinal } \\
\text { scale from very } \\
\text { healthy (0) to not } \\
\text { healthy (3) }\end{array}$ & $\begin{array}{l}\text { 4-point ordinal } \\
\text { scale from never } \\
\text { (0) to regular ( } 3 \text { ) } \\
\text { for consumption of } \\
\text { beer, wine, liquor, } \\
\text { or mixed drinks }\end{array}$ & $\begin{array}{l}\text { 4-point ordinal } \\
\text { scale from weekly } \\
\text { (0) to never (3) }\end{array}$ & $\begin{array}{l}\text { Metric: number of } \\
\text { cigars, pipes, and } \\
\text { cigarettes per day: }\end{array}$ \\
\hline Survey year & $\begin{array}{l}\text { Every second wave } \\
2004-2012\end{array}$ & $\begin{array}{l}\text { Every second wave } \\
\text { 2006-2010 }\end{array}$ & $\begin{array}{l}\text { Irregularly, with } 14 \\
\text { years between } \\
\text { 1992-2011 }\end{array}$ & $\begin{array}{l}\text { Every second wave } \\
2002-2012\end{array}$ \\
\hline Estimator & BUC & BUC & BUC & FMM \\
\hline
\end{tabular}

Table 2

BUC estimates for diet, alcohol, and physical activity

\begin{tabular}{|c|c|c|c|}
\hline & \multicolumn{3}{|c|}{ Variables } \\
\hline & $(1)$ & $(2)$ & (3) \\
\hline & Diet & Alcohol & Physical \\
\hline \multirow[t]{2}{*}{$\begin{array}{l}\text { Unemployed because of plant closure (exogenous } \\
\text { layoff) }\end{array}$} & $.2742 *$ & -.2893 & $-.1730 * *$ \\
\hline & $(.1510)$ & $(.2430)$ & $(.0796)$ \\
\hline \multirow[t]{2}{*}{ Unemployed for other reasons (endogenous layoff) } & .0005 & $.3288 * * *$ & $.0997^{* * *}$ \\
\hline & $(.0523)$ & $(.0797)$ & (.0299) \\
\hline$N$ & 29,913 & 12,146 & 168,005 \\
\hline
\end{tabular}


Table 3

FMM and OLS estimates for smoking

\begin{tabular}{|c|c|c|c|}
\hline & \multicolumn{3}{|l|}{ Models } \\
\hline & $(1)$ & $(2)$ & (3) \\
\hline & FMM (NEGBIN) & FMM (NORMAL) & POOLED OLS \\
\hline \multicolumn{4}{|l|}{ Component 1 (FMM)/Main (OLS) } \\
\hline \multirow{2}{*}{$\begin{array}{l}\text { Unemployed because of plant closure } \\
\text { (exogenous layoff) }\end{array}$} & -.3023 & .0157 & .6421 \\
\hline & $(.4461)$ & $(.5296)$ & $(.4020)$ \\
\hline \multirow{2}{*}{$\begin{array}{l}\text { Unemployed for other reasons } \\
\text { (endogenous layoff) }\end{array}$} & $.4082^{* *}$ & -.2208 & $.6036 * * *$ \\
\hline & $(.1619)$ & $(.2002)$ & $(.1547)$ \\
\hline Component mean & .8214 & 14.00 & \\
\hline \multicolumn{4}{|l|}{ Component 2 (FMM) } \\
\hline \multirow{2}{*}{$\begin{array}{l}\text { Unemployed because of plant closure } \\
\text { (exogenous layoff) }\end{array}$} & -.0221 & -4.074 & \\
\hline & $(.0329)$ & $(2.874)$ & \\
\hline \multirow{2}{*}{$\begin{array}{l}\text { Unemployed for other reasons } \\
\text { (endogenous layoff) }\end{array}$} & .0011 & $3.251 * *$ & \\
\hline & $(.0151)$ & $(1.484)$ & \\
\hline Component mean & 16.14779 & 26.66806 & \\
\hline$N$ & 55,038 & 18,721 & 55,038 \\
\hline $\operatorname{adj} . R^{2}$ & & & 0.0830 \\
\hline
\end{tabular}




\section{Appendix:}

Table A 1: Interaction effects

\begin{tabular}{|c|c|c|c|c|}
\hline & Diet & Alcohol & Physical activity & Smoking \\
\hline & (1) & (2) & (3) & (4) \\
\hline \multicolumn{5}{|l|}{ Age } \\
\hline exogenous layoff & -0.3142 & -0.5197 & -0.1403 & $5.4557 * * *$ \\
\hline exogenous layoff*age & 0.0009 & 0.0055 & -0.0008 & $-0.1134 * * *$ \\
\hline endogenous layoff & 0.2379 & -0.3241 & $0.3197 * * *$ & $-1.9161 * * *$ \\
\hline endogenous layoff*age & -0.0060 & -0.0001 & $-0.0058^{*}$ & $0.0647 * * *$ \\
\hline Age & $-0.0269 * * *$ & $-0.0256 * *$ & $-0.0392 * * *$ & $-0.0231 * * *$ \\
\hline \multicolumn{5}{|l|}{ Marital Status } \\
\hline exogenous layoff & -0.1132 & -0.4317 & $-0.2274 *$ & 0.5854 \\
\hline exogenous layoff*married & -0.0760 & -0.0502 & $0.2422 * * *$ & $-2.0525 * * *$ \\
\hline endogenous layoff & -0.0051 & $-0.3824 * * *$ & 0.0325 & $0.6022^{* *}$ \\
\hline endogenous layoff*married & -0.2241 & 0.2293 & 0.0959 & 0.1011 \\
\hline Married & 0.0092 & 0.1004 & $0.1149 *$ & 0.0364 \\
\hline \multicolumn{5}{|l|}{ Job type } \\
\hline exogenous layoff (blue collar sample) & -0.1152 & $-1.6013^{* *}$ & $-0.3732^{* * *}$ & -0.0118 \\
\hline endogenous layoff (blue collar sample) & $-0.3473 * * *$ & -0.2095 & $0.1035^{*}$ & $0.7084^{* *}$ \\
\hline exogenous layoff (white collar sample) & -0.2818 & 0.1906 & 0.0040 & $0.9828 * *$ \\
\hline endogenous layoff (white collar sample) & 0.0032 & $-0.3819 * * *$ & $0.1188^{* * *}$ & $0.5472 * * *$ \\
\hline \multicolumn{5}{|l|}{ Household Income } \\
\hline exogenous layoff & -.4091782 & $-1.201523^{* *}$ & $-.6386494 * * *$ & -.1919428 \\
\hline exogenous layoff* HH_Income(t) & .0000383 & $.0003451^{* *}$ & $.0001935 * * *$ & .000335 \\
\hline endogenous layoff & -.0110409 & -.1829726 & -.0287517 & $1.472201 *$ \\
\hline endogenous layoff* HH_Income(t) & 0.000 & -.000057 & $.0000525^{* *}$ & $-.0003378^{*}$ \\
\hline $\mathrm{HH}$ Income(t) & $-.0000255^{*}$ & .0000211 & $-.0000328 * *$ & -.0000509 \\
\hline
\end{tabular}

Notes: All regressions contain similar control variables as the main results in table 2 and 3. Columns 1-3 are estimated using BUC, column 4 uses OLS. Robust standard errors clustered on the individual level in parentheses. ${ }^{*} p<0.1,{ }^{* *} p<0.05,{ }^{* * *} p<0.01$ 